\title{
On the effects of implantation temperature in helium implanted silicon
}

\author{
E. Oliviero, M. L. David, M. F. Beaufort, and J. F. Barbot ${ }^{\text {a) }}$ \\ Laboratoire de Métallurgie Physique UMR6630, Université de Poitiers, SP2MI, Bd Marie et Pierre Curie, \\ BP30960 Futuroscope-Chasseneuil Cedex, France \\ A. van Veen \\ Interfaculty Reactor Institute, Delft University of Technology, Mekelweg 15, 2629 JB Delft, The Netherlands
}

(Received 19 June 2002; accepted 4 October 2002)

\begin{abstract}
$\mathrm{He}^{+}$ions were implanted into silicon with a fluence of $5 \times 10^{16} \mathrm{~cm}^{-2}$ at different temperatures ranging from 473 to $1073 \mathrm{~K}$. Samples were analyzed by thermal helium desorption spectroscopy and by transmission electron microscopy. As far as cavity formation is concerned, the behavior can be divided into three stages depending on the implantation temperature. However, it is found that helium release from cavities is governed by a single mechanism regardless of the implantation temperature. (C) 2002 American Institute of Physics. [DOI: 10.1063/1.1525059]
\end{abstract}

With the miniaturization of microelectronic devices, the purity requirements of semiconductors become extremely severe. In particular, the density of metallic impurities in the active region of the devices must be extremely low. Such an impurity level can only be reached by a gettering treatment. In the last few years, work ${ }^{1,2}$ has shown that helium induced cavities in silicon can be used as very efficient gettering sites. Cavities in silicon are usually formed by high dose $\mathrm{He}$ ion implantation. During subsequent annealing at temperatures above $700{ }^{\circ} \mathrm{C}$, bubbles grow and $\mathrm{He}$ is released from them by gas outdiffusion, leading to void formation, i.e., empty cavities. Metallic impurities can be trapped on the cavities at their internal surfaces. ${ }^{1}$ Numerous studies have been performed varying implantation parameters ${ }^{3}$ to optimize cavity formation. The effects of varying the implantation temperature have, however, not received much attention. In this letter, a combination of thermal helium desorption spectroscopy (THDS) and transmission electron microscopy (TEM) was used to study the effect of implantation temperature.

All the experiments were performed on commercial $n-n^{+}$silicon wafers. The $n$-type layer was epitaxially grown on a $\langle 111\rangle$ orientated $n^{+}$substrate of Czochralski silicon. The doping concentration of the $100 \mu \mathrm{m}$ thick $n$ region was $1 \times 10^{14} \mathrm{P} \mathrm{cm}^{-3}$. These samples were implanted to a constant dose of $5 \times 10^{16}$ ions $\mathrm{cm}^{-2}$ with $50 \mathrm{keV}$ helium ions $(R p=500 \mathrm{~nm}$ and $\Delta R p=140 \mathrm{~nm}$ according to SRIM calculations). ${ }^{4}$ The beam current was kept at $40 \mu \mathrm{A}$. The structure of the implantation damage was studied with crosssectional TEM using a JEOL 200 CX operating at $200 \mathrm{kV}$. In order to study cavities with minimal contrast from the unavoidable accompanying lattice damage, specimens were tilted from their $\langle 110\rangle$ orientation by few degrees in order to reduce diffraction effects. They were also imaged in underfocus and overfocus conditions to highlight the cavity edges with Fresnel contrast. THDS measurements were performed in an ultrahigh vacuum chamber $\left(10^{-8} \mathrm{~Pa}\right)$. Helium desorption was monitored using a quadrupole mass spectrometer

\footnotetext{
a) Author to whom correspondence should be addressed; electronic mail: jean.francois.barbot@univ-poitiers.fr
}

Balzers QMG 111B while the sample was annealed with a constant heating rate of $5 \mathrm{~K} / \mathrm{s}$.

The thermal desorption spectrum of helium from the sample implanted at $473 \mathrm{~K}$ is shown in Fig. 1(a). Helium release clearly occurs partially at a low temperature from 700 to $900 \mathrm{~K}$ and in a high-temperature regime centered at about $1300 \mathrm{~K}$ with all the helium being released by $1400 \mathrm{~K}$. For implantation at $673 \mathrm{~K}$, helium release occurs only in the high-temperature regime [Fig. 1(b)]. However, a shoulder peak appears toward the low-temperature side, near $1000 \mathrm{~K}$. For implantation at $773 \mathrm{~K}$, this shoulder peak is clearly defined [Fig. 1(c)]. With a further increase in implant temperature, the amount of helium retained in the sample after implantation decreases significantly. Desorption measurements with the quadrupole in scanning mode were thus performed. In this mode, the quadrupole is made to scan over a range of masses during a short time $(220 \mathrm{~ms})$. This allows one to distinguish the helium desorbing from the sample and the contribution of the background signal. The results presented in Fig. 2 (873 K implantation) clearly show that helium release occurs near $1300 \mathrm{~K}$, and that the background signal is low. Only $0.02 \%$ of the implanted helium has been found to remain in the sample implanted at $873 \mathrm{~K}$. Similar results were obtained for implantation at $1073 \mathrm{~K}$, where the helium content is even lower, $0.01 \%$. In Fig. 3, we have plotted the percentage of helium retained in the as-implanted sample against the implant temperature. These values have been obtained by integrating the desorption curves in Fig. 1 and taking into account the sensitivity of each measurement. TEM images are also presented to show the defects generated by the implants. Cavities are created following implants in the range $473-873 \mathrm{~K}$ whereas only $\{113\}$ defects are observed at higher temperatures. Previous detailed TEM study ${ }^{5}$ has shown that the formation of cavities can be divided into three stages depending on the implant temperature. As seen, helium release can also be divided into three stages. At low temperatures (between 473 and $\sim 573 \mathrm{~K}$ ), while the cavity density decreases significantly due to the dynamic annealing, the cavity mean radius and the amount of helium stay relatively constant; around $90 \%$ of the implanted helium is retained in the sample. A direct consequence is expected to be 


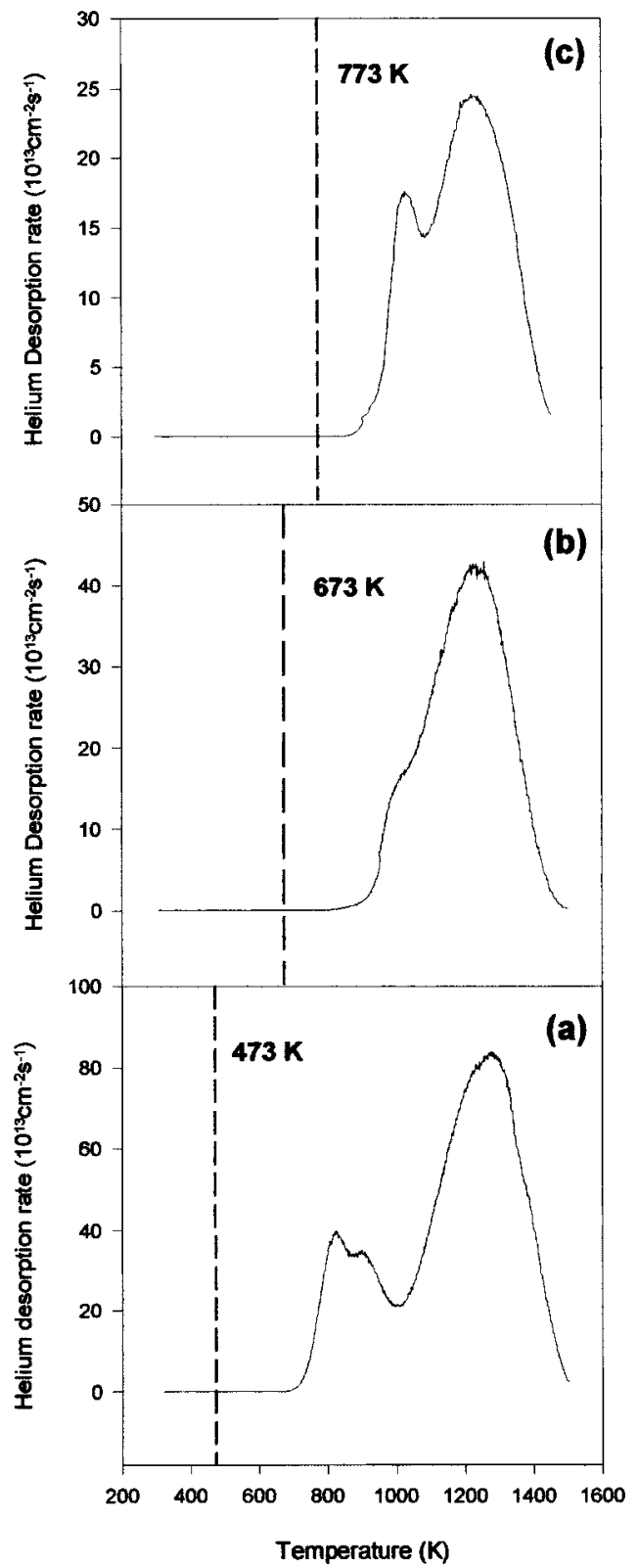

FIG. 1. Helium desorption spectrum obtained after helium implantation at (a) $473 \mathrm{~K}$, (b) $673 \mathrm{~K}$, and (c) $773 \mathrm{~K}$ in silicon $\left(5 \times 10^{16} \mathrm{~cm}^{-2}, 50 \mathrm{keV}\right)$. Heating rate: $5 \mathrm{~K} / \mathrm{s}$. The dashed line indicates the temperature of implantation.

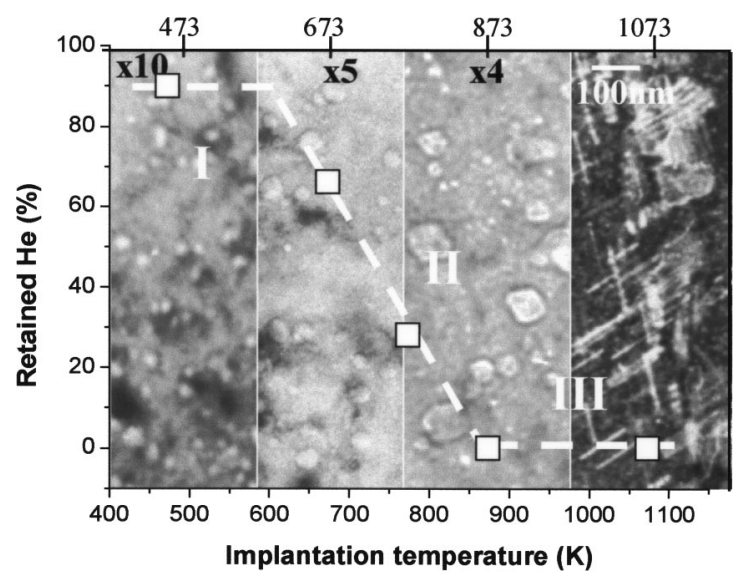

FIG. 3. Helium retained in the silicon sample after helium implantation $\left(5 \times 10^{16} \mathrm{~cm}^{-2}, 50 \mathrm{keV}\right)$, vs the implantation temperature. In the background, typical TEM images are presented in bright-field underfocus conditions for the 473,673 , and $873 \mathrm{~K}$ implantations and in weak-beam dark-field conditions $(\mathrm{g}, 7 \mathrm{~g})$ for the $1073 \mathrm{~K}$ implantation.

the formation of overpressurized cavities as discussed later. On increasing the implant temperature up to $873 \mathrm{~K}$, the amount of helium decreases linearly whereas the cavity density and radius are constant. From $573 \mathrm{~K}, \mathrm{He}$ atoms become mobile and divacancies are no longer stable. Thus, He can easily escape from the matrix during implantation. But cavities are still observed even at $873 \mathrm{~K}$. Small clusters can thus migrate and/or dissociate leaving both mobile helium and vacancy agglomerates. Some of these clusters will interact with other more stable clusters leading to larger $\mathrm{He}_{n}-V_{m}$ agglomerates and finally cavities. Helium desorption from small unstable vacancy clusters, has been previously reported for temperature as low as $400 \mathrm{~K}^{6}{ }^{6}$ The cavities become more and more faceted as the temperature increases, and finally, at a higher temperature (1073 K), no more cavities are observed. Helium is known to be the vital component in cavity formation so that even at high temperatures, it is the agglomeration of gas and vacancies that leads to cavity formation. However, the present results could indicate that only a relatively low amount of helium is necessary for cavity formation at a high temperature.

Two processes are distinguished to describe the helium release from silicon. The low-temperature part of the spectrum is generally due to helium release from interstitial positions and/or from small unstable defects. This involves diffusion of helium through the silicon lattice. In our study, this

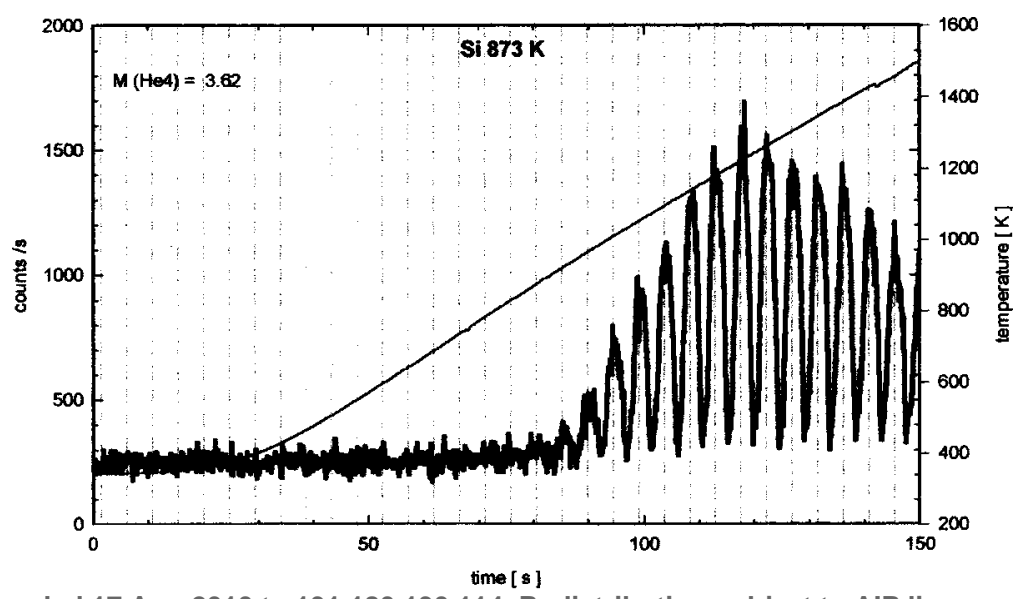

FIG. 2. Helium desorption spectrum obtained after helium implantation at $873 \mathrm{~K}$ in silicon $\left(5 \times 10^{16} \mathrm{~cm}^{-2}\right.$, $50 \mathrm{keV}$ ) while scanning from mass 3.2 to 4.03 . Scanning speed $10 \mathrm{~s} / \mathrm{amu}$. Heating rate: $5 \mathrm{~K} / \mathrm{s}$. The dashed lines indicate the mass of ${ }^{4} \mathrm{He}$. 


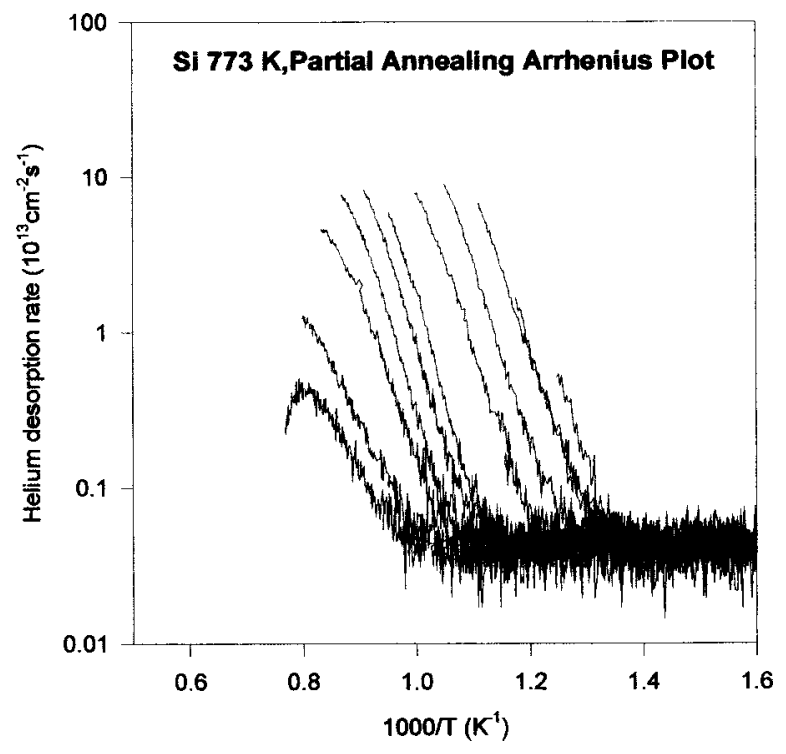

FIG. 4. Partial annealing Arrhenius plots derived from the desorption measurements of the silicon sample implanted with helium at the indicated temperature $\left(50 \mathrm{keV}\right.$ and $\left.5 \times 10^{16} \mathrm{~cm}^{-2}\right)$. Heating rate: $5 \mathrm{~K} / \mathrm{s}$.

is never observed since the implantations were carried out at high temperatures. As for helium release in the hightemperature part of the spectrum, this is due to permeation from cavities to the surface. ${ }^{6,7}$ This process also involves diffusion of helium through the silicon lattice however the limiting process is the penetration of $\mathrm{He}$ in the cavity into the silicon matrix. The peak observed close to $1300 \mathrm{~K}$ for $473-$ $873 \mathrm{~K}$ implantation temperatures is thus identified as a release by permeation from interior cavities. The twin peaks at 800-900 K observed for the $473 \mathrm{~K}$ implantation are similar to that due to the desorption from cavities but shifted toward the low-temperature part. They are ascribed to pressurized helium bubbles. Indeed, the increase of the pressure in a bubble considerably enhances the detrapping probability. The effect is attributed to the entropy change. In a bubble at high pressure, the entropy of the gas will be lower than in a cavity. The entropy difference $\Delta S=S($ dissolved $\mathrm{He})-S(\mathrm{He}$ in bubbles) will be increased leading to a shift of the temperature of maximum release toward the low-temperature part. Such a shift in temperature, assigned to pressurized bubbles, has been already observed in argon-irradiated silicon. ${ }^{8}$ The temperature of maximum release as well as the full width at half maximum (FWHM) value observed are in line with the calculated values for a bubble diameter of $1 \mathrm{~nm}$. Moreover, the dark contrast visible in the TEM image (Fig. 3) around some of the bubbles is also consistent with an overpressurized state. ${ }^{9}$ The shoulder peak near $1000 \mathrm{~K}$ appearing for the 673 and $773 \mathrm{~K}$ implantations could be also related to the nucleation of larger overpressurized bubbles. The temperature of maximum release and the FWHM value are in agreement with a bubble size of $3 \mathrm{~nm}$. For an implantation temperature of $1073 \mathrm{~K}$, the very small helium release detected can not be attributed to permeation from cavities since none of them are observed by TEM. However, recent experiments have shown that stable cavity precursors are formed during implantation at $1073 \mathrm{~K}$. These precursors have been pointed out by using multiple implants. ${ }^{10} \mathrm{It}$ is thus probable that the small amount of helium detected for the
TABLE I. Activation energy for He permeation from bubbles in silicon.

\begin{tabular}{ccccc}
\hline \hline \multicolumn{3}{c}{ Implantation parameters } & & \\
\cline { 1 - 3 } $\begin{array}{l}\text { Energy } \\
(\mathrm{keV})\end{array}$ & $\begin{array}{c}\text { Dose } \\
\left(\mathrm{He} \mathrm{cm}^{-2}\right)\end{array}$ & $\begin{array}{c}\text { Temperature } \\
(\mathrm{K})\end{array}$ & $\begin{array}{c}\text { Activation energy } \\
(\mathrm{eV})\end{array}$ & Source \\
\hline 2.5 & $2 \times 10^{16}$ & RT & 1.70 & Ref. 6 \\
1600 & $5 \times 10^{16}$ & RT & 1.83 & Ref. 11 \\
50 & $5 \times 10^{16}$ & $473-873$ & 1.80 & This work \\
\hline \hline
\end{tabular}

$1073 \mathrm{~K}$ implantation is released from stable cavity precursors.

Samples were also subjected to partial annealing (Fig. 4); they were annealed by steps with a temperature increment of $50 \mathrm{~K}$, instead of a single continuous run. This method keeps the release rates low, i.e., prevents the saturation of the quadrupole, and allows a better analysis of the desorption mechanism. Considering that the release is a first-order desorption process and that for the initial part of each desorption curve the number of filled traps $(N)$ is constant, the Arrhenius graph of the release rate versus $1 / T$ can be plotted (Fig. 4). The release rate of helium from bubbles in silicon can be written ${ }^{6}$ as

$$
\frac{d N}{d t}=A \exp \left(-\frac{\Delta H}{k T}\right),
$$

where $\Delta H$ is the activation enthalpy for permeation $(\mathrm{eV})$ and $k$ the Boltzmann constant $\left(\mathrm{eV} \mathrm{K}^{-1}\right)$. The activation enthalpy for permeation can be derived from the slopes of the curves in the partial annealing Arrhenius plot. The partial annealing results obtained for the different samples show that the helium release mechanism is always governed by single activation energy of $1.8 \mathrm{eV}$ regardless of the implantation temperature. This value is equal to those already found in case of room-temperature (RT) implantations, ${ }^{6,11,12}$ see Table I.

The present work has shown that helium release from cavities is governed by a single mechanism, the permeation from cavity, independent of implantation temperature. Moreover, it appears that only a relatively low amount of helium is necessary for cavity formation when implanting at a high temperature.

${ }^{1}$ D. M. Follstaedt, S. M. Myers, G. A. Petersen, and J. W. Medernach, J. Electron. Mater. 25, 157 (1996)

${ }^{2}$ V. Raineri, P. G. Fallica, and S. Libertino, J. Appl. Phys. 78, 3727 (1995).

${ }^{3}$ V. Raineri, M. Saggio, and E. Rimini, J. Mater. Res. 15, 1449 (2000).

${ }^{4}$ J. F. Ziegler, J. P. Biersack, and U. Littmark, The Stopping and Range of Ions in Solids (Pergamon, New York, 1985).

${ }^{5}$ M. L. David, M. F. Beaufort, and J. F. Barbot, J. Appl. Phys. (to be published).

${ }^{6}$ C. C. Griffioen, J. H. Evans, P. C. de Jong, and A. van Veen, Nucl. Instrum. Methods Phys. Res. B 27, 417 (1987).

${ }^{7}$ A. van Veen, A. H. Reader, D. J. Gravesteijn, and A. van Gorkum, Thin Solid Films 241, 206 (1993).

${ }^{8}$ A. van Veen, in Fundamental Aspects of Inert Gases in Solids, NATO ASI Series B, Physics Vol. 279, edited by S. E. Donnelly and J. H. Evans (Plenum, New York, 1991), pp 41-57.

${ }^{9}$ P. F. P. Fichtner, J. R. Kaschny, R. A. Yankov, A. Mücklich, U. Kreißig, and W. Skorupa, Appl. Phys. Lett. 70, 732 (1997).

${ }^{10}$ M. L. David, A. Ratchenkova, E. Oliviero, M. F. Denanot, M. F. Beaufort, A. Declémy, C. Blanchard, N. N. Gerasimenko, and J. F. Barbot, Nucl. Instrum. Methods Phys. Res. B (to be published).

${ }^{11}$ S. Godey, E. Ntsoenzok, T. Sauvage, A. van Veen, F. Labohm, M. F. Beaufort, and J. F. Barbot, Mater. Sci. Eng., B 73, 54 (2000).

${ }^{12}$ A. van Wieringen and N. Warmoltz, Physica (Utrecht) 22, 849 (1956). 